NOTES

\title{
Surface Characterization of Atactic Poly(methyl methacrylate) Aggregates Using Atomic Force Microscopy
}

\author{
Jijun WANG, Yanhong LuO, and Deyan SHEN ${ }^{\dagger}$ \\ State Key Laboratory of Polymer Physics and Chemistry, Institute of Chemistry, \\ Chinese Academy of Sciences, Beijing 100080, China
}

(Received January 15, 2002; Accepted May 3, 2002)

KEY WORDS Atactic Poly(methyl methacrylate)/ Dendritic Aggregates / Solvent / Substrate /

Stereoregular poly(methyl methacrylate) (PMMA) recently has been attractive to many researchers. For the mixture of isotactic and syndiotactic poly(methyl methacrylate) (i-PMMA and s-PMMA) leads to formation of a stereocomplex which was revealed a double stranded helical structure in suitable solvents. ${ }^{1,2}$ As for atactic poly(methyl methacrylate), Spevacek et al. and Borchard et al. proved that stereocomplex was able to form in its solution. ${ }^{3-5}$ And a stereocomplex was also found in atatic PMMA film from strong complexing solvent acetone. ${ }^{6,7}$ In this note, the effects of solvent and substrate on the patterning of a-PMMA aggregates were studied using by atomic force microscopy (AFM).

\section{EXPERIMENTAL}

The average molecular weight of commercial aPMMA was determined by means of gel permeation chromatography (PL-GP210), $M_{\mathrm{W}}=43.3 \times 10^{4}$, $M_{\mathrm{W}} / M_{\mathrm{n}}=1.34$. The tacticities of a-PMMA were determined by ${ }^{1} \mathrm{H}$ NMR, the proportions of iso, hetero, and syndio triads were $9 \%, 34 \%$, and $57 \%$ respectively. Average segment lengths of $\mathrm{mm}$ and $\mathrm{rr}$ (monomer unit) of atactic PMMA are 1.53 and 4.35 , respectively. The glass transition temperature $\left(T_{\mathrm{g}}=112^{\circ} \mathrm{C}\right)$ was determined by DSC at $10^{\circ} \mathrm{C} \mathrm{min}{ }^{-1}$ rate. The solutions of atactic PMMA in acetone and chloroform solvents were prepared with the concentration of $1 \mathrm{~g} \mathrm{~L}^{-1}$, and equilibrated for one week at room temperature.

Surface topography measurements were performed on a nanoscope III Muti-Mode AFM of Digital Instruments in tapping mode. The images were obtained at room temperature in air. The solutions were spancast onto silicon wafer, mica and glass with the rotating speed of $3000 \mathrm{rpm}$. Silicon and glass were cleaned by acetone solvent then by hexane solvent prior to the
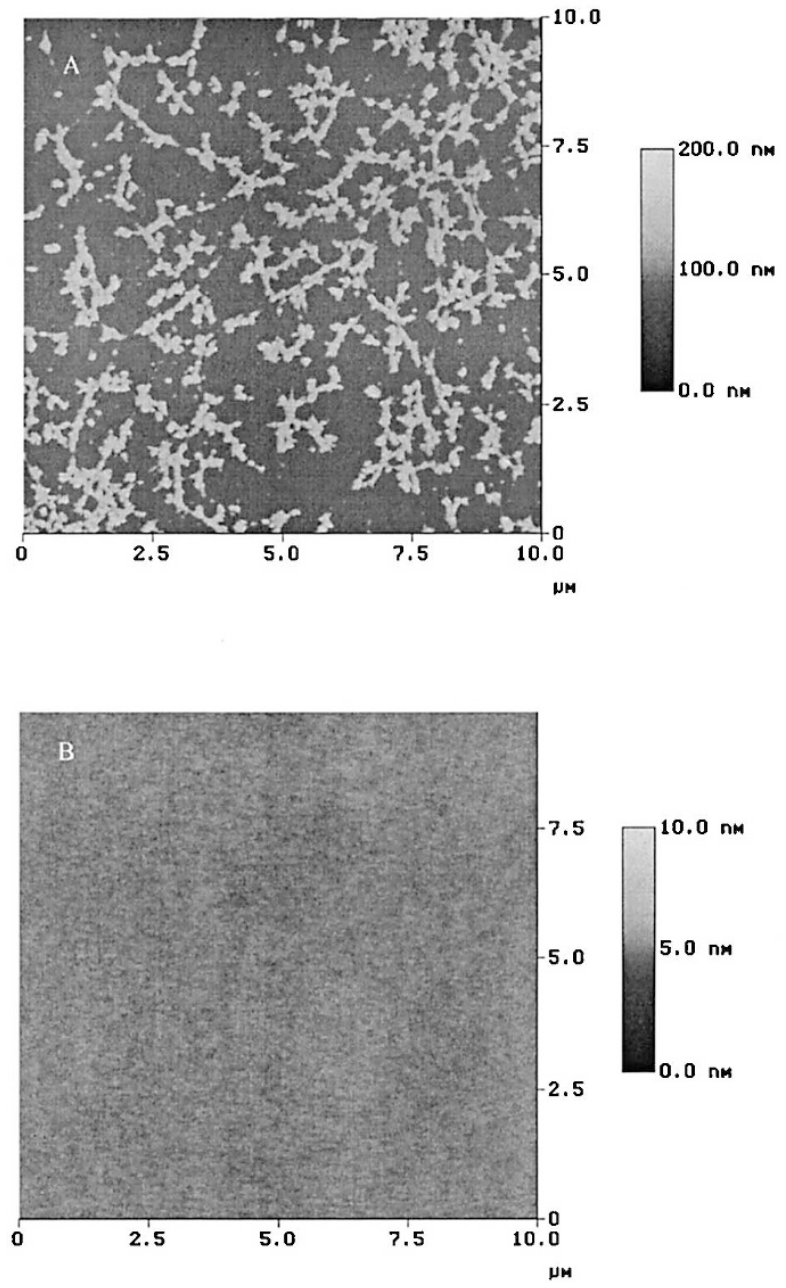

Figure 1. AFM images of aggregates of atactic PMMA spincast from acetone and chloroform solutions at a concentration of $1 \mathrm{~g} \mathrm{~L}^{-1}$ on silicon wafer. (A) acetone, (B) chloroform.

polymer deposition. Fresh mica layer was used.

${ }^{\dagger}$ To whom correspondence should be addressed (E-mail: dyshen@pplas.icas.ac.cn). 

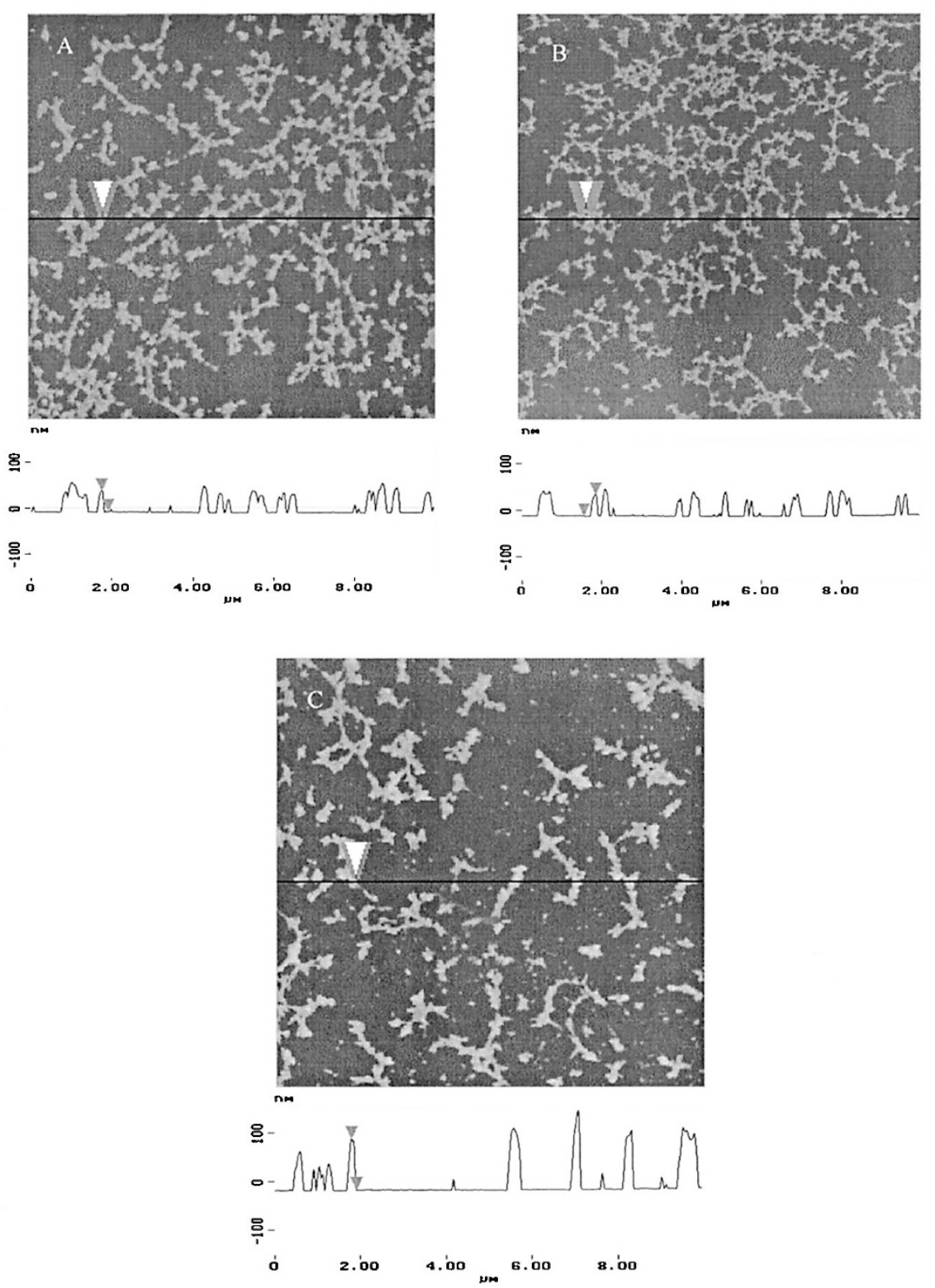

Figure 2. $A F M$ images $(10 \times 10 \mu \mathrm{m}, \mathrm{z}=300 \mathrm{~nm})$ of atactic PMMA aggregates from acetone solution at a concentration of $1 \mathrm{~g} \mathrm{~L}^{-1}$ on the different substrates and the corresponding height at $z$-axis direction. (A) silicon wafer, (B) mica, and (C) glass.

\section{RESULTS AND DISCUSSION}

The AFM image of atactic PMMA aggregates on silicon wafer from strong complexing solvent acetone was shown in Figure 1A. It indicates that the aggregates exhibit a dendritic structure. Its morphology is very similar with that of stereocomplex aggregates of the mixture of isotactic PMMA and syndiotactic PMMA with ratio $\mathrm{i} / \mathrm{s}=1 / 2$ which was observed by Grohens et al. ${ }^{8}$ Aggregation on substrate was a non-equilibrium process, its morphology was related to many factors, such as solvent, substrate, temperature, concentration, and so on. We will mainly discuss the effect of solvent and substrate in detail here.

The AFM image of a-PMMA from non-complexing solvent chloroform on silicon wafer was shown in Figure 1B. It is clear that the chloroform solution provided a homogeneously flatten morphology on the silicon wafer. Comparing the morphology of a-PMMA from chloroform solution with that from acetone solution, it is evident that the solvent nature is a predominant factor on the patterning of a-PMMA aggregates on a substrate. The state of a-PMMA in the solution affects its aggregation behavior on a substrate. Spevacek et al. and Borchard et al. have proved that stereocomplex was able to form in atactic PMMA solutions. ${ }^{3-5}$ Studying with DSC and FT-IR, ${ }^{6,7}$ we also found that a stereocomplex formed in atactic PMMA film from strong complexing acetone, while not in that from noncomplexing chloroform. Stereocomplex in the film derived from the solution from which the film was cast. 
Acting as a joint between molecular chains, stereocomplex leads to many molecular chains interaction and interpenetration each other in solution, so it is suppose that stereocomplex in atactic PMMA solution may play a role in the formation of dendritic morphology of aPMMA aggregates on the substrate.

The AFM images of a-PMMA aggregates from acetone solvent on silicon wafer, mica and glass were shown in Figure 2. It can be seen that a-PMMA aggregates show a similar dendritic patterning on these substrates. The evident differences among them were the sizes of aggregates. It can be seen that the dendritic aggregates of a-PMMA spread extensively on silicon wafer and mica, while sparsely packed on glass. At the same time, the even height of the aggregates at $z$-axis direction on glass ( $103.8 \mathrm{~nm}$ or so) was about twice of that on silicon wafer ( $45.0 \mathrm{~nm}$ or so) and mica ( $44.3 \mathrm{~nm}$ or so). Dewetting effect on substrate would be responsible for the different sizes of PMMA aggregates on the substrates. Moreover, surface energy of three kinds of substrates was different. It leads to different interaction between PMMA and substrates, which would also at- tribute to the different sizes of PMMA aggregates on the substrates.

Acknowledgment. We gratefully acknowledge financial support from National Natural Science Foundation of China under Grant No. 20023003.

\section{REFERENCES}

1. E. Schomaker and G. Challa, Macromolecules, 22, 3337 (1989).

2. T. Serizawa, K. I. Hamada, T. Kitayama, N. Fujimoto, K. Hatada, and M. Akashi, J. Am. Chem. Soc., 122, 1891 (2000).

3. W. Borchard, M. Pyrlik, and G. Rehage, Makromol. Chem., 145, 169 (1971).

4. W. Borchard, G. Kalawrytinos, B. Mohadjer, M. Pyrlik, and G. Rehage, Angew Makromol. Chem., 29/30, 471 (1973).

5. J. Spevacek and I. Fernandez-Pierola, Makromol. Chem., 188, 851 (1987).

6. Q. Gu, R. Song, and D. Y. Shen, Polym. Bull., 44, 533 (2000).

7. J. J. Wang, J. Zhao, G. Gu, and D. Y. Shen, Macromol. Rapid Commun., 22, 948 (2001).

8. Y. Grohens, G. Castelein, P. Carriere, J. Spevacek, and J. Schultz, Langmuir, 17, 86 (2001). 